\title{
Stereotactic linac radiosurgery for arteriovenous malformations
}

\author{
B G Kenny, E R Hitchcock, G Kitchen, A E Dalton, D A Yates, S V Chavda
}

University of

Birmingham, Midland

Centre for

Neurosyrgery and

Neurology,

Birmingham, UK

Department of

Neurosurgery

B G Kenny

E R Hitchock

Department of

Neuroradiology

D A Yates

S V Chavda

Wolverhampton Royal

Hospital,

Wolverhampton, UK

Radiotherapy

Department

G Kitchen

A E Dalton

Correspondence to:

B G Kenny, Midland Centre for Neurosurgery and

Neurology, Holly Lane,

Smethwick, Birmingham B67 7JX, UK

Received 25 April 1991

and in revised form

25 October 1991.

Accepted 11 December

1991

\begin{abstract}
Stereotactic linear accelerator (linac) radiosurgery has been in operation in the West Midlands since 1987 , the first of its kind in the United Kingdom. Forty two patients with high-flow cerebral arteriovenous malformations have been treated, 26 of whom have been followed up. Angiography one year after treatment showed that five lesions were obliterated, 11 were reduced in size and/or flow rate and 10 were unchanged. Overall results show that nine out of 10 patients reviewed at 24 months had total obliteration. Three patients had complications; one has fully recovered, one died of an unrelated cause at 36 months and the other died from recurrent haemorrhage at nine months. Two patients had recurrent non-fatal haemorrhage within 24 months of treatment; both recovered without further deficit. All patients are fit to work but eight are unemployed. Although the follow up period is short, the early results indicate a success rate similar to those published by others using linac radiosurgery.
\end{abstract}

The annual haemorrhage rate for untreated arteriovenous malformation (AVMs) is about $3 \%^{1}$ with a long term mortality of $17-29 \%^{23}$ and morbidity of $20-27 \% .^{1-3}$ Clinical attitudes to their management have now become more aggressive. The best results achieved by microsurgical excision vary from a mortality of $0 \cdot 9-18 \cdot 8 \%$ and morbidity of $4 \cdot 6-15 \cdot 5 \% .^{4-7}$ These risks, which are highest for large or eloquently situated lesions, encouraged the use of other treatments. These included external beam irradiation started by Magnus in 1913, and which still continues to be used. ${ }^{9}$ The potential of radiotherapy was realised with the angiographic demonstration of obliteration of some $\mathrm{AVMs}^{1011}$ accompanied by clinical improvement.

In the 1950s Leksell conceived the idea of using stereotactically-guided external irradiation to produce a predictable irradiation effect at an accurately defined intracranial target. ${ }^{12}$ After extensive experimentation he developed the first generation cobalt gamma unit in 1968. ${ }^{13}$ He called the technique "Radiosurgery" to emphasise the difference between this and conventional irradiation techniques. Kjellberg and Fabrikant developed similar radiosurgical systems based on the Bragg peak principle using proton and helium beams ${ }^{14} 15$ generated by cyclotrons. The high installation and running costs of the gamma unit and Bragg peak systems led several groups to develop radiosurgical systems using standard or modified linear accelerators (linac) ${ }^{16-19}$ The mortality from recurrent haemorrhage following radiosurgery for AVM with the gamma unit, Bragg peak and linac techniques is $1 \cdot 7-4 \%$, with permanent morbidity of $2-5 \%{ }^{20-24}$ which compares favourably with surgery.

We describe the method of linac radiosurgery for AVMs developed at the Midland Centre for Neurosurgery and Neurology (MCNN) and Wolverhampton Royal Hospital (WRH), which is the first of its kind in the UK, and includes examples of lesions treated.

\section{Materials and methods}

Forty two patients, 23 male and 19 female (age range 7-65 years, mean 34 years) were treated. Patients included acute admissions and specific referrals for radiosurgery from other regional and overseas neurosurgical and neuroradiological specialities. The presenting event was an intracerebral, intraventricular or subarachnoid haemorrhage in 25 patients $(60 \%)$. Epilepsy was present in 24 patients $(57 \%)$, and the only symptom in 16 patients $(38 \%)$.

Twenty four lesions (57\%) were situated in the left hemisphere, $15(36 \%)$ in the right and three $(7 \%)$ centrally. Lesions were approximated as spherical targets and ranged from 5-75 mm (mean $22 \mathrm{~mm}$ ) in diameter. Three patients $(7 \%)$ previously had one or more attempts at surgical excision and in four patients $(10 \%)$ embolisation had been attempted. One patient had conventional irradiation more than five years before treatment with stereotactic radiosurgery.

Patients were admitted for treatment for five to seven days. None was treated in the acute post-haemorrhagic phase and neurological status was either stable or improving at the time of treatment. All had routine neurological examination and investigation including CT and, in some instances, MRI. Outpatient follow up was performed a few weeks after discharge and thereafter at three and six months. Patients were readmitted at 12 and 24 months for repeat angiography, CT and/or MRI. Karnofsky ${ }^{25}$ scores were obtained for all admissions and follow up reviews.

\section{Stereotactic technique}

Once informed consent had been obtained the Hitchcock stereotactic frame, ${ }^{26}$ (DP Medical, 
UK), a light alloy square (wt $700 \mathrm{~g} / 1.5 \mathrm{lb}$ ) which works on the isocentric arc principle, was applied to the unshaven head under local anaesthesia and secured rigidly to the skull by three pins. General anaesthesia was used in two children aged seven and nine years. In common with most commercially available systems, geomechanical accuracy of the stereotactic system is $\leqslant 1 \mathrm{~mm}$. Angiographic and CT targeting of the lesion is carried out in relation to the stereotactic square and the data used to calculate the precise target for irradiation. Radiotherapy took place at a different site (WRH); the patient wore the square for $24-48$ hours and was encouraged to mobilise normally. The square was well tolerated and no patient has failed to complete the treatment protocol. On return from radiotherapy, the square was removed.

\section{Angiographic technique}

Angiography was performed with a Siemens Angioskop Digitron 3 under local anaesthesia (LA) via a transfemoral route. Individually marked, purpose built, angiographic targeting grids which can be attached above or below the stereotactic square permit a complete range of oblique projections including extreme Townes views. From orthogonal stereoscopic views with a $10^{\circ}$ separation, the lesion diameters were noted, the volume calculated, and the geometric centre of the lesion marked. Magnification was eliminated by directly measuring dimensions against the grid graduations. The final target isocentre was calculated graphically and confirmed by a simple computer program, thus reducing observer error.

\section{Treatment planning and irradiation}

The stereotactic square was fixed to the CT couch in a head frame adaptor and aligned using vertical and horizontal laser lights. By placing the isocentre of the stereotactic square to that of the CT computer (IGE 8800), stereotactic and CT coordinates became identical. The radiotherapy planning computer requires direct scan data in the form of axial and oblique reformats taken in the planes of proposed irradiation arcs. To conform with the seven arc method used, reformats are taken at $0,30,60,90,120,150$ and 180 degrees around the isocentre chosen from the angiogram. The lesion diameter can be measured again on the CT image and outlined using the cursor trace facility. An advantage of this method of targeting is that it gives an excellent view of surrounding structures and this information can be used to tailor the dose and shape to suit the clinical situation. Isodose contours were calculated and configured to the lesion allowing for adjacent vulnerable structures. The CT arc reformats allowed skull thickness and depth of lesion to be included directly into dose calculations, and appropriate adjustments were made to the arc doses.

Patients were irradiated with multiple noncoplanar arcs of $100-150^{\circ}$ on a Phillips SL7514 Linear Accelerator which produces a highly acceptable isodose profile compared with other techniques. ${ }^{27}$ Purpose built collimators of
Table Results of follow up

\begin{tabular}{lr}
\hline Overall status at $1-2$ years $(n=26)$ & No $(\%)$ \\
\hline Obliterated & $9(35 \%)$ \\
Reduced & $7(27 \%)^{\star}$ \\
Unchanged & $10(38 \%)^{\star}$ \\
Total & 26 \\
\hline
\end{tabular}

${ }^{\star}$ Note: 16 of 17 patients in the reduced and unchanged groups have not yet reached two year review.

$10 \mathrm{~mm}, 12 \mathrm{~mm}, 15 \mathrm{~mm}, 17 \mathrm{~mm}$ and $20 \mathrm{~mm}$ were used to improve spatial accuracy and provide a steep edge cutoff; this was $2 \mathrm{~mm}$ from the $90 \%$ to the $50 \%$ isodose line using the $10 \mathrm{~mm}$ collimator. The dose range used was 12.5-50 Gy (mean 26.7 Gy); the lower doses were given to the larger lesions.

\section{Results}

All results refer to patients followed up for $12-24$ months (range for all patients is $3-47$ months) with angiography and CT. Twenty six patients have been followed up for 12 months and 10 patients for 24 months.

The overall results are illustrated in the table. One year after treatment five lesions (19\%) were obliterated, $11(42 \%)$ were reduced in size and/or flow rate on comparable angiography and $10(38 \%)$ showed no change. Four of the five patients who required angiography at 24 months had complete obliteration. Nine of 10 AVMs ranging in diameter from 5-40 $\mathrm{mm}$ which we have followed up for two years have been totally obliterated. Several examples of total and partial obliteration are illustrated in the figure (A-H).

Although five patients had perilesional low density change on CT scans only three of them had clinical evidence of oedema. One of these patients died of recurrent haemorrhage at nine months and another died at 36 months from a pulmonary embolus. In both cases the cause of death was confirmed at necropsy. The third patient is asymptomatic without treatment at 47 months after treatment. Of the three patients with recurrent haemorrhage, two recovered without new neurological deficit. All patients returned to their previous occupations except eight who are fit to work but unemployed. Karnofsky performance scores, ${ }^{25}$ which had improved significantly by the time of treatment, revealed no deterioration related to radiosurgery afterwards.

\section{Discussion}

Surgical excision remains the treatment of choice for AVM in accessible sites. The relatively large number of dominant hemisphere and central lesions in our series reflects the higher risks associated with these lesions. Published series of stereotactic radiosurgery report obliteration rates of $67 \cdot 5-86 \cdot 5 \%$ at two years. ${ }^{20}$ Nine of our 10 patients reviewed for 24 months or more had complete obliteration of their AVM. Eleven AVMs (42\%) were reduced in size and/or flow rate at 12 months indicating the effect of irradiation. Our results suggest a similar pattern of overall success to published series. 


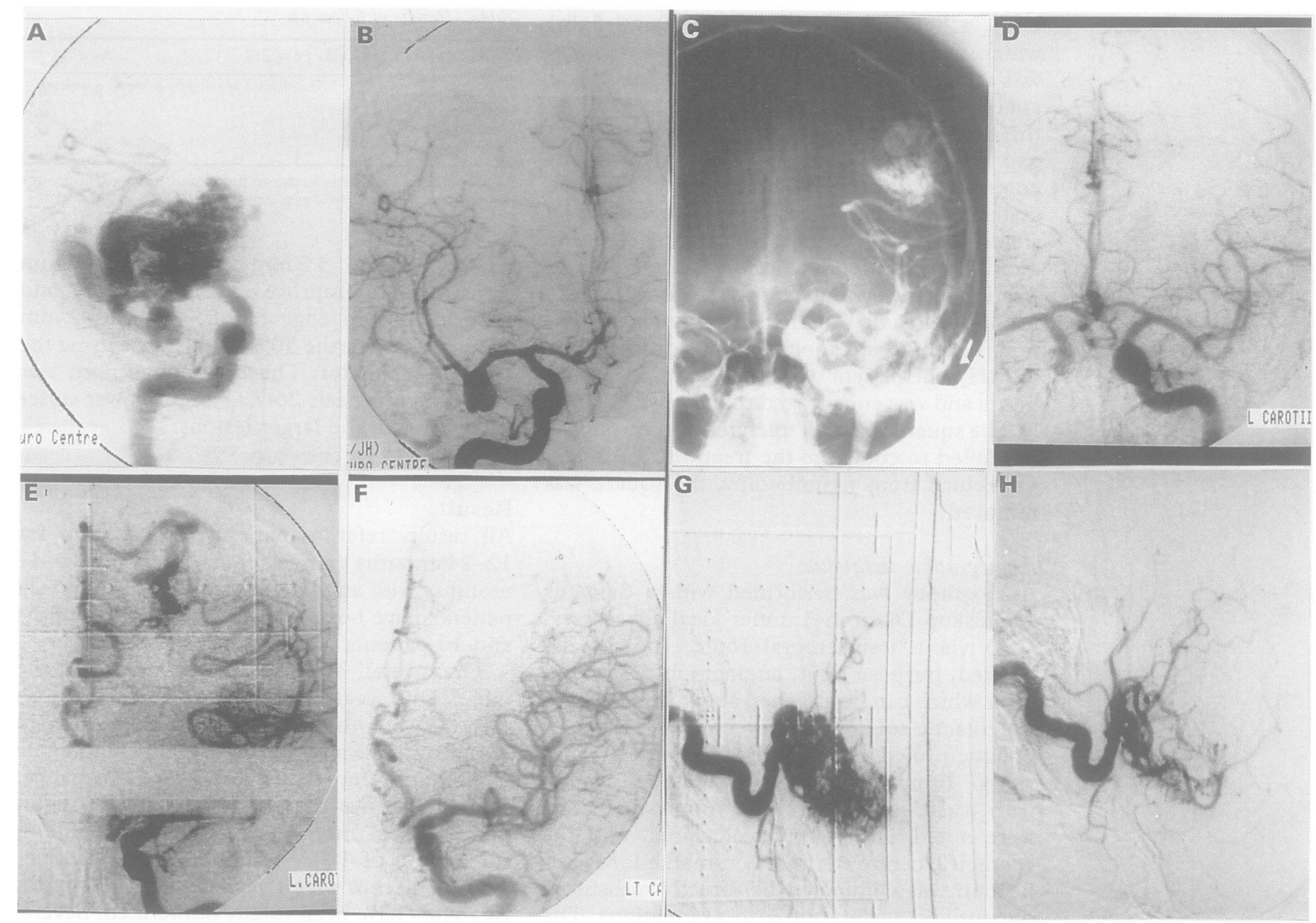

Figure A-H: Pre-(A) and post-(B) irradiation angiogram showing complete obliteration of AVM with filling of normal anterior and middle cerebral vessels as a result of shunt reversal in a patient with a coexisting aneurysm. Two AVMs (C and E) pre-irradiation completely obliterated at two year follow up (D and $F)$. Pre-irradiation $A V M(G)$ reduced in size and flow at one year follow up antiogram $(H)$.

The risk of recurrent haemorrhage remains unchanged for two years after radiosurgery with any of the currently available techniques. The mortality from such events, however, is lower than that expected from the natural history of AVMs, ${ }^{20}$ presumably due to changes in the vascular endothelium. The patient in our series who had a third intraventricular haemorrhage from a hypothalamic AVM illustrates the increased risk of mortality from repeated haemorrhage. $^{2}$

Temporary or permanent neurological deterioration attributable to irradiation and accompanied by imaging evidence of low density change occur in $2-4 \%$ of reported series. ${ }^{20}$ Low density change adjacent to the target area in asymptomatic patients has been reported, ${ }^{28}$ and we observed this in two patients.

AVMs may be regarded as having an arterial feeding, and a venous draining phase, constituting the nidus of the lesion. ${ }^{29}$ The relative importance of the components of the nidus in terms of radio-obliteration is not clear but may be critical to the success of treatment. In small AVMs the entire volume may be targeted and the obliteration rate is highest in this type of lesion. ${ }^{20}$ In large lesions ( $>3 \mathrm{~cm}$ diameter), the same argument cannot be applied as the risk of radionecrosis is dose/volume related. ${ }^{30}$ If late phase films are used, the aprarent volume of the AVM may be misleading. Targeting larger volumes is more hazardrus and the treatment of such lesions remains problematical. It is possible to totally obliterate larger AVMs by targeting only the nidus, ${ }^{24}$ but peripheral parts may remain unchanged. ${ }^{2831}$ Another possible solution is to use fractionation. There are considerable stereotactic problems associated with fractionation, however, and the radiobiological rationale of such a regime, which is well established in tumour therapy, may not apply to AVMs. The volume irradiated could also be reduced by partial embolisation, a technique which has been successfully combined with surgery. ${ }^{32}$ In our series larger lesions were either treated selectively or with small doses.

Dose regimes vary between units and techniques, although it is apparent that there is a tendency to lower total doses. ${ }^{2830}$ Except for our first patient, who received $50 \mathrm{~Gy}$, all other patients received $40 \mathrm{~Gy}$ or less and the mean dose for our series is $26.7 \mathrm{~Gy}$. Only long term follow up will reveal how successful this dose range proves to be.

The reported incidence of epilepsy following excision of AVMs was $57 \%^{33}$ in one series, $75 \%$ of whom developed epilepsy within two years of operation. As yet, none of our patients has developed de novo epilepsy or EEG changes. Reduction in the frequency and/or severity of seizures has been reported following radiosurgery ${ }^{34}$ and several of our patients had such an improvement. 
A variety of arc arrangements are used by different groups. The most common are multiple non-coplanar converging techniques. However, innovative systems involving simultaneous linac head and couch head rotation have also been developed. ${ }^{35}$ These rotation systems may produce a more suitable isodose configuration than simpler existing systems. As yet, not enough clinical data exist to confirm this.

Because the accuracy of all stereotactic radiosurgical techniques is within that of stereotactic targeting instrumentation, there is nothing to choose between the various radiosurgical systems so far as accuracy is concerned. The gamma unit and Bragg peak systems are expensive to install and run. This study shows that linac radiosurgery using a locally available and easily modifiable standard linear accelerator produces highly acceptable results.

We thank the radiographers and nurses of the Midland Centre for Neurosurgery and Neurology, Wolverhampton Royal Hospital, Photographic Department SDGH, and W Mitchell and $B$ Pope for the design and construction of the angiographic grids.

1 Crawford PM, West CR, Chadwick DW, Shaw MDM Arteriovenous malformations of the brain: natural history in unoperated patients. I Neurol Neurosurg Psychiat in unoperated

2 Foster DMC, Steiner L, Hakanson S. Arteriovenous malformation of the brain. A long term clinical study. Neurosurg 1972;37:562-70

3 Brown RD, Wiebers DO, Forbes G, et al. The natural history of unruptured intracranial arteriovenous malformations. f Neurosurg 1988;68:352-7.

4 Suzuki J, Onuma T, Kayama T. Surgical treatment of arteriovenous malformations. Neurol Res 1982;4: 191-207.

5 Fults D, Kelly DL. Natural history of arteriovenous malformations of the brain: a clinical study. Neurosurg 1984;15:658-62.

6 Davis C, Symon L. The management of cerebral arteriovenous malfor

7 Heros RC Korosue K, Diebold PM. Surgical excision of arteriovenous malformations: late results. Neurosurg 1990;26:570-8.

8 Magnus V. Bidag Ttil Hjernechirugiens Klinik og Resultater. ristiania, Merkur, 1921.

9 Poulsen MG. Arteriovenous malformations-a summary of 6 cases treated with radiation therapy. Int $\mathcal{f}$ Radiat Oncol Biol Phys 1987;13:1553-7.

10 Johnson RJ. Radiotherapy of cerebral angiomas with a note on some problems of diagnosis. In: Pia HW, Gleave JRW, Grok E, Zierski J, eds. Cerebral Angiomas: Advances in Diagnosis and Therapy. Berlin: Springer-Verlag, 1975 256-9.

11 Tognetti F, Andreoli A, Cuscini A, Testa C. Successful management of an intracranial arteriovenous malformation by conventional irradiation. $f$ Neurosurg 1985; 63:193-5.

12 Leksell $\mathrm{L}$. The stereotaxic method and radiosurgery of the brain. Acta Chir Scand 1951;102:316-9

13 Leksell L. Stereotactic Radiosurgery. $\mathcal{F}$ Neurol Neurosurg Psychiatry 1983;46:797-803.

14 Kjellberg RN. Stereotactic Bragg peak proton beam radiosurgery for arteriovenous malformation of the brain. Clin Neurosurg 1984;31:248-90.

15 Fabrikant JI, Lyman JT, Hosobuchi Y. Stereotactic heavyion Bragg peak radiosurgery: method for treatment of deep arteriovenous malformations. $B r F$ Radiol 1984; 57:479-90.

16 Colombo F, Benedetti A, Pozza F, et al. External stereotactic irradiation by linear accelerator. Neurosurgery 1985;16: 154-60.

17 Betti O, Derechinsky V. Irradiation stereotaxique multifaisceaux. Neurochir 1983;29:295-8.

18 Winston MD, Lutz W. Linear accelerator as a neurosurgical tool for stereotactic radiosurgery. Neurosurg 1988; 22:454-64

19 Hitchock ER, Kitchen G, Dalton E, Pope B. Stereotacti LINAC radiosurgery. Br $\mathcal{f}$ Neurosurg 1989;3:305-12.

20 Ogilvy CS. Radiation therapy for arteriovenous malformations: a review. Neurosurg 1990;26:725-35.

21 Steiner L, Linquist C. Radiosurgery in cerebral arteriovenous malformations. In: Tasker RR, ed. Neurosurgery: state of the art reviews vol 2, Stereotactic Surgery. Philadelphia: Hanley and Belfus, 1987:329-36.

22 Kemeny AA, Dias P, Forster DMC. Results of stereotactic radiosurgery of arteriovenous malformations: an analysis radiosurgery of arteriovenous malformations: an analysis $554-8$.

23 Colombo F, Benedetti A, Pozza F, Marchetti C, Chierego G. Linear accelerator radiosurgery of cerebral arteriovenous malformations. Neurosurg 1989;24:833-40.

24 Betti OO, Munari C, Rosler R. Stereotactic radiosurgery with the linear accelerator: treatment of arteriovenous malformations. Neurosurg 1989;24:311-21.

25 Karnofsky DA, Abelmann WH, Craver LF, Burchonal JH. The use of nitrogen mustards in the palliative treatment of carcinoma. Cancer 1948;1:634-56.

26 Hitchcock ER. The Hitchcock system. In: Lundsford ED. Modern stereotactic neurosurgery. Boston: Martinus Nijhoff, 1988:47-61.

27 Podgorsak EB, Pike GB, Olivier A, Marina PLA, Souhami L. Radiosurgery with high energy photon beams: a comparison among techniques. Int f Radiat Oncol Biol comparison among tech

28 Fabrikant JI, Levy RP, Frankel KA, et al. Stereotactic helium ion radiosurgery for the treatment of intracranial arteriovenous malformations. In: Heikkinen ESA, Kiviniitty K. Proceedings, International workshop on proton and narrow photon beam therapy. Finland: University of Oulu, 1989:33-7.

29 Doppman JL. The nidus concept of spinal cord arteriovenous malformations. $\mathrm{Br} \mathcal{F}$ Radiol 1971;44:758-63.

30 Kjellberg RN, Hanamura T, Davis KR, Lyons SL, Adams RD. Bragg-peak proton-beam therapy for arteriovenous malformations of the brain. NEngl $f$ Med 1983 309:269-74

31 Steiner L, Leksell L, Forster DMC, Greitz T, Backlund E-O. Stereotactic radiosurgery in intracranial arteriovenous malformations. Acta Neurochir Suppl 1974; venous mal

32 Spetzler RF, Martin NA, Carter PL, Flom RA, Raudzens PA, Wilkinson E. Surgical management of large AVMs by staged embolisation and operative excision. $\mathcal{F}$ Neurosurg 1987;67:17-28.

33 Crawford PM, West CR, Shaw MDM, et al. Cerebral arteriovenous malformations and epilepsy: factors in the development of epilepsy. Epilepsia 1986;27:270-5.

34 Heikkinen ER, Kiviniitty K, Vayrynen T, et al. Effects of proton or photon therapy of cerebral arteriovenous malformations on symptomatic epilepsy. In: Keikkinen ESA, Kiviniitty K, eds. Proceedings, International workshop on proton and narrow photon beam therapy. Finland: University of Oulu, 1989:77-81.

35 Podgorsak EB, Olivier A, Pla M, Lefebvre P-Y, Hazel J. Dynamic stereotactic radiosurgery. Int $\mathcal{F}$ Radiat Oncol Biol Phys 1988;14:115-26. 